\title{
Disparities in Health Outcomes of Return Migrants in Mexico
}

\author{
Fernando A. Wilson, ${ }^{1}$ Jim P. Stimpson, ${ }^{1}$ and José A. Pagán ${ }^{2,3,4}$ \\ ${ }^{1}$ Department of Health Services Research and Administration, College of Public Health, University of Nebraska Medical Center, \\ Omaha, NE 68198-4350, USA \\ ${ }^{2}$ Center for Health Innovation, The New York Academy of Medicine, New York, NY 10029, USA \\ ${ }^{3}$ Leonard Davis Institute of Health Economics, University of Pennsylvania, Philadelphia, PA 19104, USA \\ ${ }^{4}$ Department of Population Health Science and Policy, Icahn School of Medicine at Mount Sinai, New York, NY 10029, USA
}

Correspondence should be addressed to Fernando A. Wilson; fernando.wilson@unmc.edu

Received 4 June 2014; Revised 5 October 2014; Accepted 7 October 2014; Published 28 October 2014

Academic Editor: Alberto Davila

Copyright (C) 2014 Fernando A. Wilson et al. This is an open access article distributed under the Creative Commons Attribution License, which permits unrestricted use, distribution, and reproduction in any medium, provided the original work is properly cited.

Objective. The epidemiological paradox posits that immigrants in USA experience better health outcomes than nonimmigrants with similar socioeconomic status. However, little is known about the development of health problems over the life course for immigrants who return to their country of origin. Methods. The Mexican Migration Project provides detailed information on immigration, health, and socioeconomic status for 671 unauthorized migrants, 101 legal migrants, and 3,748 nonmigrants. Cox regression estimated the adjusted hazard of developing hypertension, diabetes/prediabetes, poor mental health, and heart and lung problems. Results. Legal immigrants to USA did not have a significantly higher risk of having a self-reported diagnosis of hypertension, diabetes, heart or lung problems, or poor mental health compared to nonmigrants. However, the hazard ratio for unauthorized deported immigrants ranged from 2.25 (CI: 1.29-3.93) for diabetes to 4.43 (CI: 2.33-8.40) for poor mental health compared to nonmigrants. Conclusions. Health problems occur several years earlier among unauthorized immigrants compared to individuals who never migrated. Poor access to healthcare services combined with USA lifestyle and working conditions after migration to the USA may contribute to an increased risk for the development of chronic health conditions later in life.

\section{Introduction}

Although a bill to provide a pathway to citizenship for immigrants who illegally crossed into USA is currently stalled in Congress, immigration reform remains a priority for the White House and continues to be a recurrent topic of debate among policymakers $[1,2]$. A pathway to citizenship would allow immigrants to benefit from state and federal health programs including the health insurance exchanges established under the Affordable Care Act (ACA) [3]. Currently, unauthorized immigrants-in addition to recent legalized immigrants-are excluded from federal health benefits programs [4]. Although there is evidence that unauthorized immigrants are less likely to utilize healthcare services than USA natives [5], it is unclear to what extent barriers to accessing healthcare services among unauthorized immigrants compromise their current health status or if return migration to their country of origin fulfills the unmet healthcare needs for this population.
Research suggests that immigrants from Latin America tend to have better than predicted health status despite having a lower socioeconomic status and restricted access to social support programs. Hispanic-origin immigrants in USA have lower mortality rates than white USA nativesa phenomenon called the epidemiological paradox, first documented by Markides and Coreil in 1986 [6]. For example, Latinos of Mexican origin have a 0.60 hazard ratio for mortality compared to non-Latino whites [7]. Other research shows similar large differences in health outcomes between Hispanic and white non-Hispanic persons [8-23]. There is evidence that living in primarily Hispanic communities is associated with a one-third decrease in infant mortality compared to communities with a small Hispanic presence [20].

Reasons for these differences are not definitive and have centered around two competing hypotheses, the healthy migrant effect and salmon bias [21-23]. The former hypothesis suggests that the health advantage of Hispanics results 
from a higher likelihood of relatively healthy persons migrating to USA, whereas the salmon bias hypothesis argues that Hispanics who fall ill in USA are more likely to return to their country of origin and, therefore, they drop out of USA records. However, compared to studies on migrants within USA, little is known about the health profile of unauthorized immigrants who return-involuntarily or voluntarily-to their country of origin. One study by Ullmann and colleagues (2011) examines rural and urban differences in health outcomes for migrants versus nonmigrants [23]. However, the study did not characterize the relationship between health outcomes and the type of migration experienced by immigrants to USA. It is also unknown whether the health profile of immigrants over the lifespan varies by their migration experience.

Our study extends findings by Ullmann and colleagues (2011) by differentiating between the health outcomes of unauthorized and legal migrants and nonmigrants and by modeling the onset of health problems over the lifespan for these groups. Many health problems manifest themselves later in life and, thus, short-term health advantages, if any, that migrants experience early in their migration history relative to nonmigrants may disappear years later. There is also the possibility that fundamental differences in health risks and, consequently, health outcomes appear later in life between migrants who cross into USA illegally, legally authorized migrants, and nonmigrants.

\section{Methods}

2.1. Data Source. The Mexican Migration Project (MMP) - a collaborative research project between Princeton University and the University of Guadalajara in Mexico-collected detailed information on Mexican heads of households concerning their migration history. MMP employs an ethnosurvey approach in which ethnographic fieldwork is combined with survey sampling to collect both qualitative and quantitative data for randomly selected households throughout Mexico. More details on the ethnosurvey approach used by MMP and its validation are provided by Massey and Zenteno (2000) [24]. To do this, communities in Mexico are sampled based on size, region, ethnic composition, and economic base. These include 22 of Mexico's 31 states. Within each community, approximately 200 households are surveyed each year during winter months in order to ensure high representation of migrant workers in the survey. Details on border crossings and the USA legal, health, and socioeconomic status of heads of household were provided. Health data were also collected for the period 2007-2013; 2013 is the most recent survey year. Migrants ranged in age from 19 to 102 years old. More information on MMP is available elsewhere [25].

Respondents were classified into four groups: unauthorized migrants with no history of deportation, unauthorized immigrants who were deported, legal migrants, and nonmigrants. Unauthorized migrants include those with at least one illegal border crossing, and unauthorized migrants were stratified by deportation history (never deported versus deported). Legal migrants include migrants to USA who have never crossed illegally, including conditional and permanent residents and naturalized citizens in USA. Nonmigrants are individuals with no history of migration to USA. There were 4,682 heads of households with nonmissing migration history. The analytical sample size was 4,520 for respondents with nonmissing health and socioeconomic measures, which included 671 unauthorized migrants, 101 legal migrants, and 3,748 nonmigrants.

2.2. Measures. Detailed information on USA-Mexico border crossings is provided for migrants including year, documentation used, length of trip, and other detailed characteristics for each crossing. Border crossings include trips by land and by air. Documentation used included type of visa, proof of U.S. citizenship, or none or false documents if unauthorized. Documentation was used to classify respondents as unauthorized or legal migrants. Respondents reporting "never migrated to USA" were classified as nonmigrants.

Outcome measures examined for this study included selfreported diagnosis of hypertension, diabetes/prediabetes, mental health, and heart and lung problems. For hypertension, respondents were asked "Have you ever had or currently have hypertension?" For diabetes/prediabetes, they were asked "Have you ever had or currently have diabetes or high sugar levels?" For mental health, they were asked "Have you ever had or currently have emotional, nerves, or psychiatric problems?" For heart problems, they were asked "Have you ever had or currently have a heart attack or heart problems?" For lung problems, they were asked "Have you ever had or currently have chronic lung conditions?" Possible responses to these questions included "Yes," "No," or "Unknown." These health conditions were selected because chronic disease and mental health are likely to be sensitive to the migration experience over the lifecycle.

Independent variables included demographic, health, and economic factors. Demographic factors included years of age, gender, years of education, and marital status. Male versus female gender adjusts for the likelihood that a head of household is more likely to be male rather than female in MMP. Health factors included smoking history (i.e., whether or not the respondent had ever smoked) and obesity status (i.e., having a body mass index (BMI) of 30 and over, where BMI is defined as self-reported weight in kilograms divided by height in meters squared). Economic factors included home ownership, number of household amenities, vehicle ownership, and ownership of a business. Respondents were asked about the tenancy of their current residence. A dichotomous variable was defined for home ownership for reporting owning versus not owning the current residence. Respondents were asked a series of questions about the availability of household amenities. Amenities included running water, electricity, sewage, stove, refrigerator, washing machine, sewing machine, radio, TV, stereo, phone, internet access, computer, and cellular phone. Possible responses included "Yes," "No," or "Unknown." A count variable was created to denote the number of household amenities reported by each respondent. For vehicle ownership, a dichotomous variable was defined based on whether a respondent owned any vehicle type versus no vehicles. Respondents were asked to list their history of business holdings. Current business 
ownership was dichotomized as having any business holdings (e.g., store, street vendor, restaurant/bar, agriculture, cattle, etc.) that were not closed at the interview time versus no business holdings.

2.3. Analytical Plan. Our approach is broadly consistent with a life-course approach in which past events in a person's life course (e.g., history of deportation) may impact subsequent events such as, in this study, the development of health issues [26-28]. Unfortunately, we do not have longitudinal data on immigrants over the life span, which prohibits a full implementation of the life-course approach. However, similar to prior studies using this approach, the Cox proportional hazards model has been used to model the impact of past events over the life-course of individuals [26]. The Cox regression model is also nonparametric and, thus, does not require any assumptions related to the distribution of the hazard rate over time $[29,30]$. Another significant advantage of the Cox model is that right censoring in the data does not confound its estimators. This is an issue for our data given that observation of respondents' health events is truncated at the date of interview. For these reasons, we use multivariate Cox regression analysis to estimate the hazard of having a chronic health problem by each year of age:

$$
\begin{aligned}
\log h_{i}(t)= & \log h_{0}(t)+\beta_{1} \text { Demographic }_{i} \\
& +\beta_{2} \text { Health }_{i}+\beta_{3} \text { Economic }_{i}+\beta_{4} \text { Year }_{i} .
\end{aligned}
$$

In the model, failure is defined as reporting a diagnosis of a health problem over the observed time interval (defined over the age of each respondent). Thus, the Cox regression model examines the hazard of developing a health problem over the lifespan of respondents. The model was adjusted for the demographic (including migration status), health, and economic factors presented above in Measures. The model also included the survey year to capture any time trends. The model was fitted using maximum likelihood, and regression results were used to generate the probability of self-reporting one of the specific health conditions of interest by year of age. All analyses adjust for sampling weights provided by MMP using Stata 12 (StataCorp, College Station, TX).

\section{Results}

Table 1 includes the summary statistics for the five selfreported health conditions analyzed in this study (heart problems, poor mental health, hypertension, lung problems, and diabetes). Respondents reporting hypertension or lung problems were more likely to be nonmigrants (86\%) than other health conditions. Nearly one out of five persons with poor mental health was unauthorized immigrant with no history of deportation. Persons reporting diabetes were most likely to be male $(82.1 \%)$ and married $(73.7 \%)$ and to own their house $(85.7 \%)$, a vehicle $(57.1 \%)$, and a business $(41.4 \%)$ compared to persons with other health conditions. Number of years of education ranged from 5.6 to 6.7 years. Likelihood of smoking was similar across the health conditions ranging from $33.5 \%$ to $35.8 \%$. Persons reporting poor mental health had the lowest rate of obesity (15.1\%) and those reporting hypertension had the highest (33.1\%). Number of home amenities ranged from 9.3 to 10.1 across the health conditions.

Table 2 presents hazard ratios from the multivariate Cox regression analysis for each health condition. Tests of the proportional hazards assumption were performed using Schoenfeld residuals for each model (see Table 3). Legal immigrants to USA did not have significantly higher risk for any of the studied health problems compared to nonmigrants. In contrast, hazard ratios were highly statistically significant for all health conditions except lung problems between unauthorized immigrants with a history of deportation and nonmigrants. The hazard ratio for unauthorized deported immigrants ranged from 2.25 (CI: 1.29-3.93) for diabetes to 4.43 (CI: $2.33-8.40$ ) for poor mental health. Unauthorized immigrants who were never deported had significantly higher hazard of heart $(\mathrm{HR}=3.26$; $\mathrm{CI}$ : 1.76-6.02), mental health $(\mathrm{HR}=5.0 ; \mathrm{CI}: 3.20-7.82)$, hypertension $(\mathrm{HR}=1.63$; CI: $1.15-2.30)$, and diabetes ( $\mathrm{HR}=1.61 ; \mathrm{CI}: 1.06-2.43)$. The hazard ratio was not statistically significant for lung problems. We also examined the development of stroke and cancer, but cell sizes were small (only $19(.4 \%)$ respondents reported having had a stroke and $43(1.0 \%)$ reported having had cancer) and results were not statistically significant (results not shown).

We also used multivariate Cox regression to model the relationship between the probability of reporting a health problem and age in years across the migrant groups. The Cox regression also adjusted for total months residency in USA, gender, education level, marital status, smoking, obesity status, home ownership, household amenities, vehicle and business ownership, and survey year. Unauthorized migrants with a history of deportation are predicted to be more likely to develop diabetes at an earlier age than other migrants (see Figure 1). Half of unauthorized immigrants who were deported are predicted to develop diabetes about 12 years earlier than their nonmigrant peers. For unauthorized immigrants who were never deported, this difference is 7 years.

Similarly, in Figure 2, the likelihood of hypertension is greater at earlier ages for unauthorized immigrants versus nonmigrants. By the age of 59, half of unauthorized, deported immigrants are predicted to have hypertension, a point reached nearly 14 years later for nonmigrants and 8 years later for unauthorized, never deported immigrants. For mental health, unauthorized immigrants who were deported have a similar probability of poor mental health as the unauthorized ones who were never deported (Figure 3). By the age of 60, $20.9 \%$ of unauthorized deported immigrants are predicted to have poor mental health compared to just $5.2 \%$ of nonmigrants. About two out of five unauthorized immigrants are predicted to develop heart problems by the age of 72 compared to $13.0 \%$ of nonmigrants (Figure 4 ). The percentages for unauthorized immigrants with or without deportation for developing heart problems are similar. Finally, Figure 5 presents results for lung problems stratified by immigration status; however, results were not statistically significant.

\section{Discussion}

This work extends prior research by differentiating between migrant groups based on respondents' migration experiences 
TABLE 1: Unadjusted weighted characteristics of respondents by self-reported health condition, Mexican Migration Project.

\begin{tabular}{|c|c|c|c|c|c|}
\hline & $\begin{array}{c}\text { Heart }^{\mathrm{a}} \\
(N=169) \\
\end{array}$ & $\begin{array}{l}\text { Poor mental health } \\
\qquad(N=268)^{\mathrm{a}}\end{array}$ & $\begin{array}{c}\text { Hypertension } \\
(N=769) \\
\end{array}$ & $\begin{array}{l}\text { Diabetes } \\
(N=504)\end{array}$ & $\begin{array}{c}\text { Lung } \\
(N=97)\end{array}$ \\
\hline \multicolumn{6}{|l|}{ Migration status, $\%$} \\
\hline Never migrated & 80.0 & 72.8 & 85.5 & 84.8 & 85.7 \\
\hline Legalized & 4.3 & 3.3 & 3.0 & 3.8 & 1.3 \\
\hline Unauthorized; never deported & 11.4 & 16.5 & 6.9 & 7.4 & 9.7 \\
\hline Unauthorized; deported & 4.2 & 7.3 & 4.7 & 4.1 & 3.3 \\
\hline Total length of time in US, months & 19.6 & 19.0 & 12.6 & 15.7 & 12.8 \\
\hline Male, $\%$ & 73.4 & 69.1 & 74.5 & 82.1 & 73.0 \\
\hline Education, years & 5.6 & 6.0 & 6.7 & 6.2 & 6.4 \\
\hline Married, \% & 64.0 & 55.6 & 67.3 & 73.7 & 58.1 \\
\hline Smoker, \% & 33.5 & 34.3 & 35.3 & 35.8 & 34.1 \\
\hline Obese, $\%$ & 24.1 & 15.1 & 33.1 & 27.4 & 19.7 \\
\hline Owns house, $\%$ & 82.4 & 76.1 & 78.5 & 85.7 & 68.6 \\
\hline Amenities, number ${ }^{\mathrm{b}}$ & 10.1 & 9.4 & 9.5 & 9.7 & 9.3 \\
\hline Owns vehicle, $\%$ & 46.9 & 39.4 & 50.4 & 57.1 & 48.1 \\
\hline Owns business, $\%$ & 38.0 & 39.2 & 35.5 & 41.4 & 33.8 \\
\hline
\end{tabular}

${ }^{a}$ Heart is defined dichotomously based on responses to the question "Have you ever had or currently have a heart attack or heart problems?" Poor mental health is defined using the question "Have you ever had or currently have emotional, nerves, or psychiatric problems?" Hypertension is defined using the question "Have you ever had or currently have hypertension?" Diabetes is defined using the question "Have you ever had or currently have diabetes or high sugar levels?" Lung is defined using the question "Have you ever had or currently have chronic lung conditions?"

${ }^{b}$ Number of amenities is defined based on respondent's reporting having running water, electricity, sewage, stove, refrigerator, washing machine, sewing machine, radio, TV, stereo, phone, internet access, computer, and cellular phone.

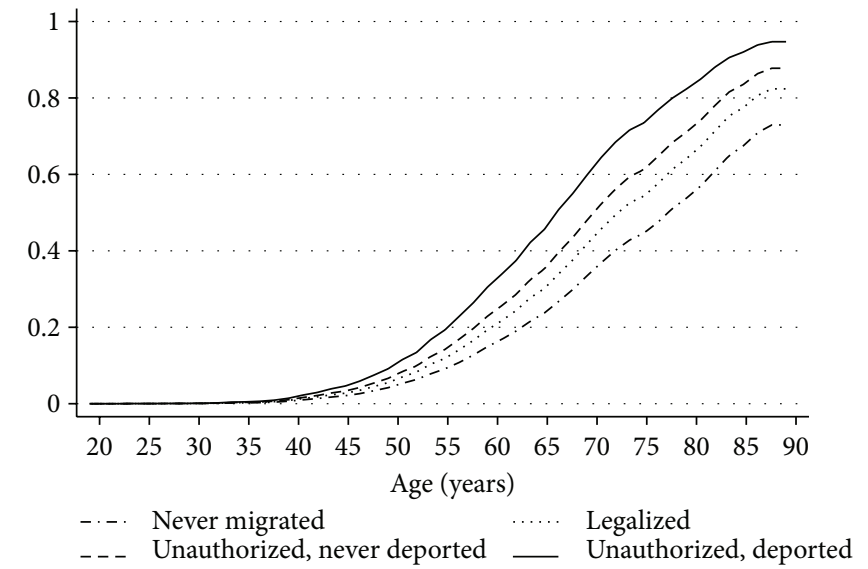

Figure 1: Cox regression-adjusted probability of developing diabetes by migrant status and age in years, Mexican Migration Project $(N=4,520)$.

and examining the hazard of developing chronic health conditions over the lifespan. Onset of chronic health conditions varies significantly among immigrants with varying migration backgrounds after adjustment for confounding factors. Migrants crossing into USA illegally are more likely to report health problems at an earlier age than nonmigrants, whereas there is no evidence that legal migrants enjoy a health advantage over nonmigrants for heart, mental health, hypertension, and lung or diabetes problems.

The health advantages immigrants in USA - particularly those of Mexican origin-enjoy over nonimmigrants have

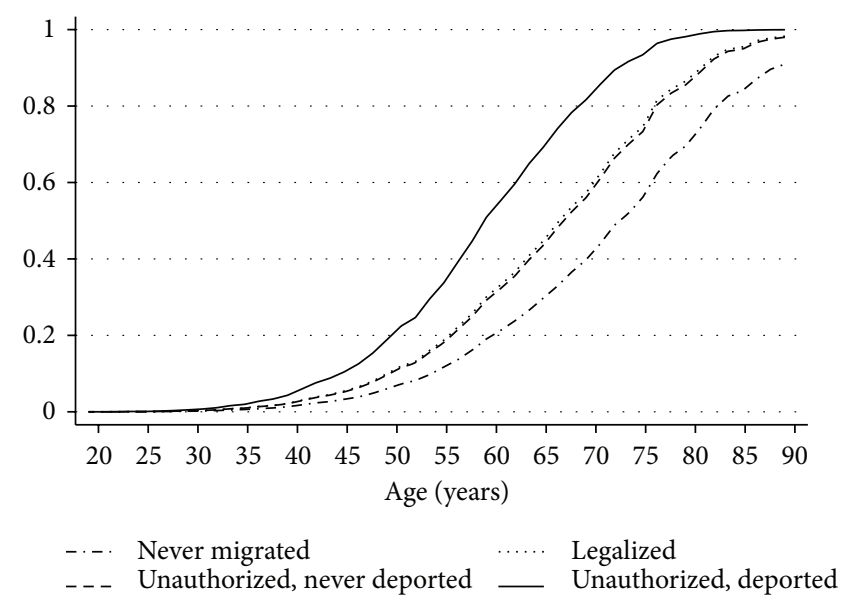

FIgURE 2: Cox regression-adjusted probability of hypertension by migrant status and age in years, Mexican Migration Project $(N=$ $4,520)$.

been well established in the literature $[6,10,11,15,17,18]$. Advantages have been shown for specific diseases as well as overall mortality $[10,11,15,17-20,31]$. For example, a recent study by Riosmena and colleagues (2013) found that immigrants display better outcomes for hypertension and obesity compared to non-Hispanic whites [32]. Female immigrants who were born in Mexico and reside in USA are significantly less likely to have preterm or low birth weight births [31].

Reasons for these health advantages have centered on two competing hypotheses, the healthy migrant effect and salmon 
TABLE 2: Hazard ratios from Cox regression of reporting health problems, Mexican Migration Project $(N=4,520)$.

\begin{tabular}{|c|c|c|c|c|c|}
\hline & $\begin{array}{l}\text { Heart }^{\mathrm{a}} \\
\mathrm{HR}(\mathrm{CI})\end{array}$ & $\begin{array}{c}\text { Poor mental health }^{\mathrm{a}} \\
\text { HR (CI) }\end{array}$ & $\begin{array}{c}\text { Hypertension } \\
\text { HR (CI) }\end{array}$ & $\begin{array}{l}\text { Diabetes } \\
\text { HR (CI) }\end{array}$ & $\begin{array}{c}\text { Lung } \\
\text { HR (CI) }\end{array}$ \\
\hline \multicolumn{6}{|l|}{ Migration status } \\
\hline Never migrated & Ref. & Ref. & Ref. & Ref. & Ref. \\
\hline \multirow{2}{*}{ Legalized } & 1.60 & 2.17 & 1.69 & 1.33 & .24 \\
\hline & $(.24,10.61)$ & $(.64,7.37)$ & $(.90,3.15)$ & $(.55,3.23)$ & $(.01,5.49)$ \\
\hline \multirow{2}{*}{ Unauthorized, never deported } & $3.26^{* *}$ & $5.0^{* *}$ & $1.63^{* *}$ & $1.61^{*}$ & 1.88 \\
\hline & $(1.76,6.02)$ & $(3.20,7.82)$ & $(1.15,2.30)$ & $(1.06,2.43)$ & $(.78,4.55)$ \\
\hline \multirow{2}{*}{ Unauthorized, deported } & $3.63^{* *}$ & $4.43^{* *}$ & $3.36^{* *}$ & $2.25^{* *}$ & 1.43 \\
\hline & $(1.37,9.60)$ & $(2.33,8.40)$ & $(2.20,5.14)$ & $(1.29,3.93)$ & $(.32,6.29)$ \\
\hline \multirow{2}{*}{ Total length of time in USA, months } & 1.0 & 1.0 & 1.0 & 1.0 & 1.0 \\
\hline & $(.99,1.0)$ & $(.99,1.0)$ & $(1.0,1.0)$ & $(1.0,1.0)$ & $(1.0,1.01)$ \\
\hline \multirow{2}{*}{ Male } & $.46^{* *}$ & $.37^{* *}$ & $.38^{* *}$ & $.64^{*}$ & .62 \\
\hline & $(.26, .82)$ & $(.22, .59)$ & $(.28, .53)$ & $(.42, .98)$ & $(.31,1.23)$ \\
\hline \multirow{2}{*}{ Education, years } & $1.04^{*}$ & $1.07^{* *}$ & $1.10^{* *}$ & $1.06^{* *}$ & $1.07^{*}$ \\
\hline & $(1.00,1.08)$ & $(1.03,1.11)$ & $(1.08,1.12)$ & $(1.03,1.08)$ & $(1.01,1.13)$ \\
\hline \multirow{2}{*}{ Married } & 1.31 & .83 & $1.55^{* *}$ & 1.36 & .72 \\
\hline & $(.77,2.22)$ & $(.55,1.25)$ & $(1.16,2.08)$ & $(.94,1.96)$ & $(.39,1.32)$ \\
\hline \multirow{2}{*}{ Smoker } & 1.08 & 1.30 & $1.25^{* *}$ & $1.23^{*}$ & 1.24 \\
\hline & $(.76,1.54)$ & $(.95,1.76)$ & $(1.05,1.47)$ & $(1.00,1.50)$ & $(.76,2.02)$ \\
\hline \multirow{2}{*}{ Obese } & 1.19 & $.62^{* *}$ & $1.79^{* *}$ & $1.39^{* *}$ & .89 \\
\hline & $(.82,1.74)$ & $(.43, .88)$ & $(1.51,2.11)$ & $(1.11,1.73)$ & $(.51,1.56)$ \\
\hline \multirow{2}{*}{ Owns house } & $.43^{* *}$ & $.46^{* *}$ & $.46^{* *}$ & $.69^{*}$ & $.35^{* *}$ \\
\hline & $(.28, .66)$ & $(.33, .63)$ & $(.38, .56)$ & $(.52, .92)$ & $(.21, .56)$ \\
\hline \multirow{2}{*}{ Amenities, number ${ }^{\mathrm{b}}$} & $1.13^{* *}$ & .98 & $.95^{*}$ & 1.01 & .98 \\
\hline & $(1.04,1.23)$ & $(.91,1.06)$ & $(.92, .99)$ & $(.96,1.06)$ & $(.88,1.10)$ \\
\hline \multirow{2}{*}{ Owns vehicle } & 1.02 & $.62^{*}$ & 1.11 & 1.23 & 1.07 \\
\hline & $(.69,1.50)$ & $(.43, .89)$ & $(.92,1.35)$ & $(.97,1.54)$ & $(.57,2.01)$ \\
\hline \multirow{2}{*}{ Owns business } & 1.13 & 1.14 & 1.01 & $1.23^{*}$ & .88 \\
\hline & $(.80,1.59)$ & $(.86,1.51)$ & $(.86,1.19)$ & $(1.01,1.51)$ & $(.55,1.43)$ \\
\hline \multicolumn{6}{|l|}{ Survey year } \\
\hline 2007 & Ref. & Ref. & Ref. & Ref. & Ref. \\
\hline \multirow{2}{*}{2008} & .77 & .97 & $1.28^{*}$ & 1.04 & .88 \\
\hline & $(.50,1.18)$ & $(.68,1.39)$ & $(1.02,1.62)$ & $(.76,1.40)$ & $(.41,1.92)$ \\
\hline \multirow{2}{*}{2009} & .72 & $2.32^{* *}$ & 1.11 & $1.73^{* *}$ & 2.14 \\
\hline & $(.39,1.31)$ & $(1.60,3.36)$ & $(.82,1.52)$ & $(1.24,2.42)$ & $(.95,4.80)$ \\
\hline \multirow{2}{*}{2010} & .64 & $.16^{* *}$ & 1.38 & 1.37 & $.10^{*}$ \\
\hline & $(.24,1.71)$ & $(.06, .42)$ & $(.94,2.03)$ & $(.83,2.27)$ & $(.01, .75)$ \\
\hline \multirow{2}{*}{2011} & .61 & $.42^{* *}$ & 1.07 & 1.36 & $2.17^{*}$ \\
\hline & $(.32,1.19)$ & $(.22, .79)$ & $(.80,1.44)$ & $(.96,1.94)$ & $(1.12,4.19)$ \\
\hline \multirow{2}{*}{2012} & $.18^{* *}$ & $.43^{* *}$ & $1.45^{* *}$ & 1.33 & 1.83 \\
\hline & $(.07, .44)$ & $(.27,68)$ & $(1.12,1.88)$ & $(.96,1.84)$ & $(.95,3.52)$ \\
\hline \multirow{2}{*}{2013} & $.48^{* *}$ & $.23^{* *}$ & .98 & 1.28 & 1.08 \\
\hline & $(.29, .79)$ & $(.13, .42)$ & $(.77,1.26)$ & $(.96,1.70)$ & $(.53,2.18)$ \\
\hline
\end{tabular}

** denotes $P$ value $<.01 ;{ }^{*}$ denotes $P$ value $<.05$. HR $=$ hazard ratio; $\mathrm{CI}=$ confidence interval.

${ }^{a}$ Heart is defined dichotomously based on responses to the question "Have you ever had or currently have a heart attack or heart problems?" Poor mental health is defined using the question "Have you ever had or currently have emotional, nerves, or psychiatric problems?" Hypertension is defined using the question "Have you ever had or currently have hypertension?" Diabetes is defined using the question "Have you ever had or currently have diabetes or high sugar levels?" Lung is defined using the question "Have you ever had or currently have chronic lung conditions?"

${ }^{b}$ Number of amenities is defined based on respondent's reporting having running water, electricity, sewage, stove, refrigerator, washing machine, sewing machine, radio, TV, stereo, phone, internet access, computer, and cellular phone. 
TABLE 3: Test of proportional-hazards assumption for Cox regression model, Mexican Migration Project $(N=4,520)^{\mathrm{a}}$.

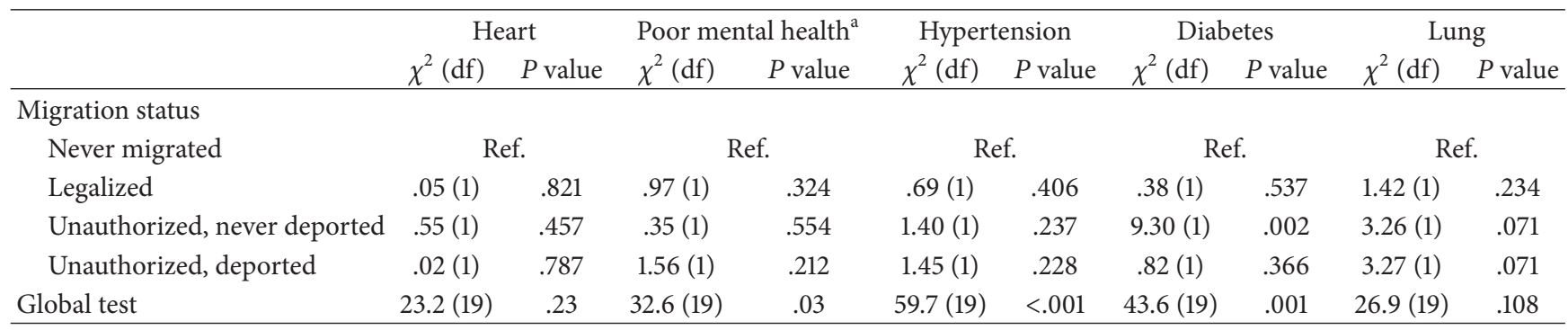

${ }^{a}$ Goodness of fit statistics for demographic, health, and economic factors are not shown.

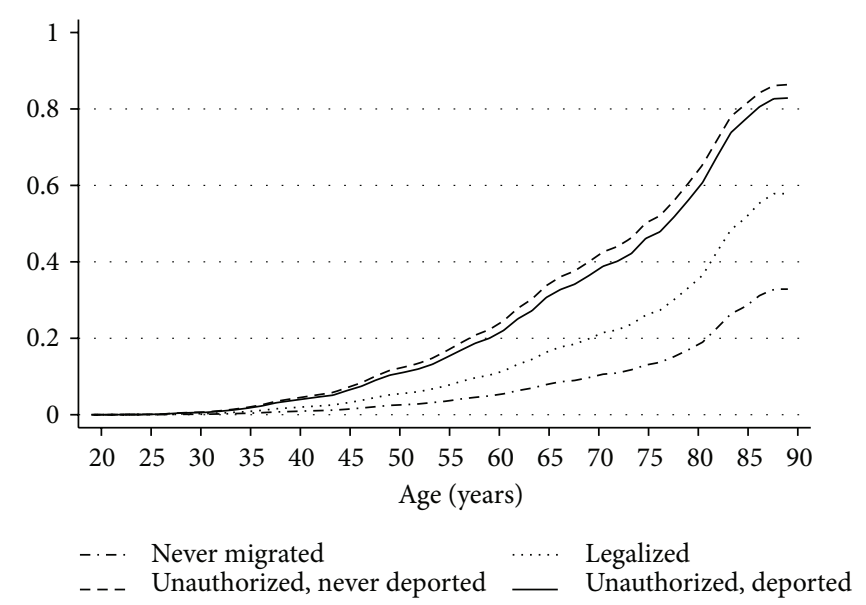

FIGURE 3: Cox regression-adjusted probability of poor mental health by migrant status and age in years, Mexican Migration Project $(N=4,520)$. (Poor mental health is defined dichotomously based on responses to the question "have you ever had or currently have emotional, nerves, or psychiatric problems?”.)

bias [21-23]. The healthy migrant hypothesis posits that the health advantage of Hispanic immigrants results from a higher likelihood of relatively healthy persons migrating to USA. However, the salmon bias hypothesis argues that Hispanics who fall ill in USA are more likely to return to their country of origin and drop out of USA records. Controversy over which hypothesis is correct has not been resolved, in part, because of limited information on the health outcomes of immigrants returning to their home country. Results from one study suggest that return Mexican immigrants tend to have poorer health than their nonmigrant peers [23]. However, there was no differentiation between migrants themselves-particularly legalized versus unauthorized immigrants - and the development of health problems over their lifespan. Our study findings suggest that unauthorized migrants are more likely to report a range of health problems significantly earlier-sometimes more than a decade earlier-compared to nonmigrants. As a result, these findings lend support to the salmon bias hypothesis as a plausible explanation of why data on immigrants residing in USA show better health outcomes than USA natives. Furthermore, based on our study results, it is unlikely that the poorer health status of unauthorized migrants relative

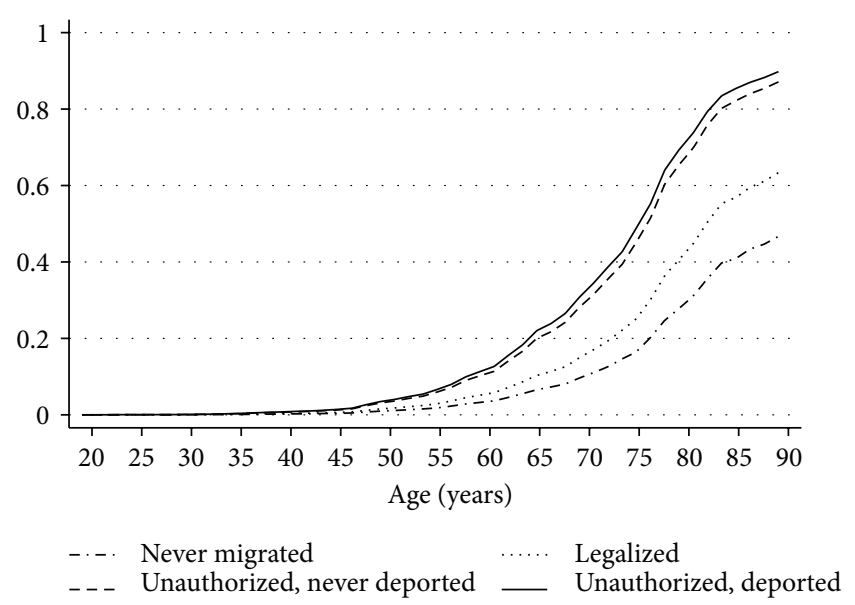

FIgURE 4: Cox regression-adjusted probability of heart problems by migrant status and age in years, Mexican Migration Project $(N=$ $4,520)$.

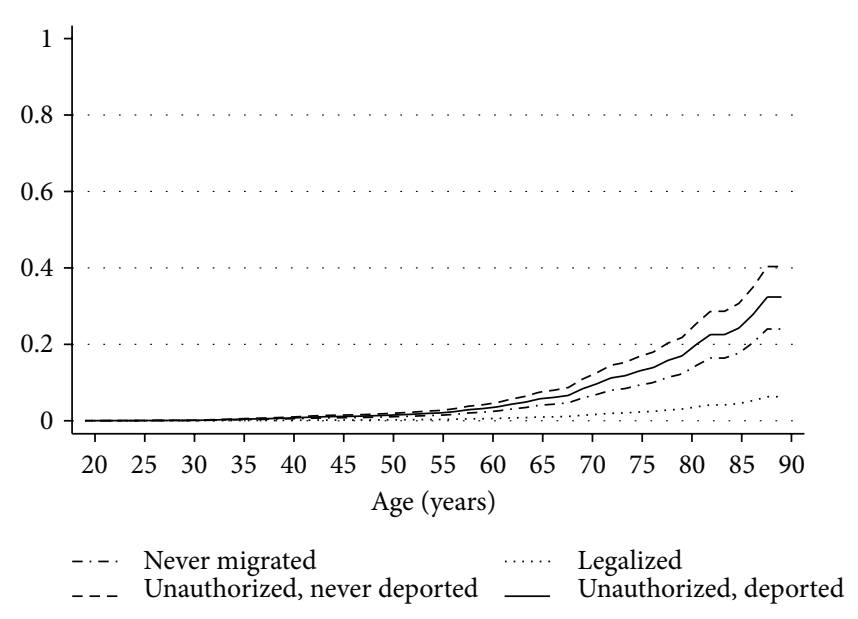

FIGURE 5: Cox regression-adjusted probability of lung problems by migrant status and age in years, Mexican Migration Project $(N=$ $4,520)$.

to nonmigrants result from socioeconomic differences. After adjustment for demographic and economic factors, unauthorized, previously deported immigrants experienced between two to four times the hazard of developing health problems compared to nonmigrants. 
Unfortunately, we do not have sufficient data to explore underlying reasons for these health disparities between unauthorized migrants and nonmigrants, but there are a number of possibilities. Immigrants-particularly unauthorized migrants-experience stressful life events resulting from adjusting to a new environment, and these events may result in adverse impacts on their life course. A recent study suggests, for example, that young immigrants experience a higher allostatic load, an indicator of chronic stress [33,34]. Chronic stress may lead to higher likelihood of developing diabetes, poor mental health, and cardiovascular disease later in life [35-39].

However, immigrants may not seek care when needed in USA because of legal and economic barriers to care such as the 1996 PRWOA which restricts access to federal social welfare programs for unauthorized and recent legal immigrants $[4,40]$. In fact, a recent study by Stimpson et al. (2013) suggests that unauthorized immigrants are less likely to utilize healthcare services and account for less healthcare expenditures per capita than legal immigrants or USA natives [5]. Legal barriers to care such as the PRWOA and limited state healthcare benefits programs for unauthorized immigrants may partially explain our findings of the poor health status of unauthorized return migrants relative to nonmigrants, and these barriers will continue to have a substantial impact on immigrant communities in USA. For example, unauthorized migrants to USA are prohibited from participating in insurance exchanges created under the Affordable Care Act, thus further limiting access to health care for this population. In addition, immigration reform efforts have stalled in the U.S. Congress $[1,2]$, and there is no indication that the 1996 PRWOA will be modified in the foreseeable future. In contrast, legalized immigrants benefit from access to ACA provisions and federally funded benefits programs unless they have less than five years of USA residency. Furthermore, naturalized citizens currently enjoy dual citizenship in both Mexico and USA and, thus, benefit from accessing healthcare services and programs of either country. These factors may explain why our study findings showed no significant differences in health problems between legalized and nonmigrants in Mexico.

It is possible that unauthorized migrants may initially be healthier relative to nonmigrants but experience a different lifestyle in USA and difficult working conditions that, in combination with poor access to health care after crossing the border, result in adverse health outcomes over time, undiagnosed chronic disease, or delayed medical treatment. Thus, ironically, the healthcare system in Mexico may be an important-and, in many cases, the only-avenue for immigrants to obtain care as they work and live in USA. In fact, results from the California Health Interview Survey indicate that having a chronic illness increases the odds of utilizing medical care in Mexico instead of in USA among Mexican immigrants [41]. A separate study showed that distance from Mexico was an important determinant in the demand for health insurance coverage by Mexican immigrants [9]. Consequently, migrants falling ill and returning to Mexico may in part explain the apparent health advantage observed in the literature for migrants remaining in USA.
4.1. Limitations. This study has a number of limitations. First, we are not able to establish causality between migration history and health outcomes because of the lack of longitudinal data on migrants. Second, we have to rely on self-reported data instead of clinically diagnosed health conditions for our outcome measures. Third, we do not have a direct measure of age of initial onset of health problems. Instead, we rely on selfreported existence of a health condition and the respondent's age at time of the interview. Finally, we cannot examine stability of return migration, that is, whether the return migration to Mexico is permanent or temporary. Future immigration plans for respondents are not available.

\section{Conclusions}

This study provides evidence that unauthorized migrants returning from USA to reside in Mexico are in significantly worse health than legal migrants and nonmigrants. Much prior research has documented the health advantages immigrants in USA have over nonimmigrants-the epidemiological paradox. However, our study suggests that these advantages do not extend to return unauthorized migrants.

The relationship between health status and immigration among Mexican citizens is complex and dependent on the particular migration circumstances faced by those choosing to migrate to USA. More research is needed to examine how USA lifestyle and working conditions as well as barriers to access to health care may explain the more adverse health trajectories experienced by unauthorized immigrants over their lifespan compared to their nonmigrant peers.

\section{Conflict of Interests}

The authors declare that there is no conflict of interests regarding the publication of this paper.

\section{References}

[1] White House, "Creating an Immigration System for the 21st Century," http://www.whitehouse.gov/issues/immigration.

[2] A. Parker, "Democrats to try long-shot tactic for house immigration vote," The New York Times, 2014, http://www.nytimes .com/2014/03/27/us/politics/democrats-to-try-long-shot-tactic-for-house-immigration-vote.html? ref=immigrationandemigration.

[3] National Immigration Law Center, Immigrants and the Affordable Care Act (ACA), June 2014, http://www.nilc.org/immigrantshcr.html.

[4] K. P. Derose, J. J. Escarce, and N. Lurie, "Immigrants and health care: sources of vulnerability," Health Affairs, vol. 26, no. 5, pp. 1258-1268, 2007.

[5] J. P. Stimpson, F. A. Wilson, and D. Su, "Unauthorized immigrants spend less than other immigrants and us natives on health care," Health Affairs, vol. 32, no. 7, pp. 1313-1318, 2013.

[6] K. S. Markides and J. Coreil, "The health of Hispanics in the southwestern United States: an epidemiologic paradox," Public Health Reports, vol. 101, no. 3, pp. 253-265, 1986.

[7] A. F. Abraído-Lanza, B. P. Dohrenwend, D. S. Ng-Mak, and J. B. Turner, "The Latino mortality paradox: a test of the "salmon 
bias" and healthy migrant hypotheses," American Journal of Public Health, vol. 89, no. 10, pp. 1543-1548, 1999.

[8] K. S. Markides and K. Eschbach, "Aging, migration, and mortality: current status of research on the hispanic paradox," Journals of Gerontology, Series B Psychological Sciences and Social Sciences, vol. 60, no. 2, pp. S68-S75, 2005.

[9] H. S. Brown, "Do Mexican immigrants substitute health care in Mexico for health insurance in the United States? The role of distance," Social Science \& Medicine, vol. 67, no. 12, pp. 20362042, 2008.

[10] R. A. Hummer, D. A. Powers, S. G. Pullum, G. L. Gossman, and W. P. Frisbie, "Paradox found (again): infant mortality among the Mexican-origin population in the United States," Demography, vol. 44, no. 3, pp. 441-457, 2007.

[11] R. A. Hummer, R. G. Rogers, S. H. Amir, D. Forbes, and W. P. Frisbie, "Adult mortality differentials among Hispanic subgroups and non-Hispanic whites," Social Science Quarterly, vol. 81, no. 1, pp. 459-476, 2000.

[12] N. Landale, R. S. Oropesa, and B. K. Gorman, "Migration and infant death: assimilation or selective migrations among Puerto Ricans?” American Sociological Review, vol. 65, no. 6, pp. 888909, 2000.

[13] A. Palloni and J. D. Morenoff, "Interpreting the paradoxical in the Hispanic paradox demographic and epidemiologic approaches," in Population Health and Aging Strengthening the Dialogue between Epidemiology and Demography, M. Weinstein, A. I. Hermalin, and M. A. Stoto, Eds., vol. 954 of Annals of the New York Academy of Sciences, pp. 140-174, 2001.

[14] C. M. Turra and I. T. Elo, "The impact of salmon bias on the hispanic mortality advantage: new evidence from social security data," Population Research and Policy Review, vol. 27, no. 5, pp. 515-530, 2008.

[15] I. T. Elo, C. M. Turra, B. Kestenbaum, and B. R. Ferguson, "Mortality among elderly Hispanics in the United States: past evidence and new results," Demography, vol. 41, no. 1, pp. 109128, 2004.

[16] A. Fenelon, "Revisiting the Hispanic mortality advantage in the United States: the role of smoking," Social Science and Medicine, vol. 82, pp. 1-9, 2013.

[17] P. D. Sorlie, E. Backlund, N. J. Johnson, and E. Rogot, "Mortality by Hispanic status in the United States," The Journal of the American Medical Association, vol. 270, no. 20, pp. 2464-2468, 1993.

[18] A. F. Abraído-Lanza, B. P. Dohrenwend, D. S. Ng-Mak, and J. B. Turner, "The Latino mortality paradox: a test of the "salmon bias" and healthy migrant hypotheses," The American Journal of Public Health, vol. 89, no. 10, pp. 1543-1548, 1999.

[19] L. Franzini, J. C. Ribble, and A. M. Keddie, "Understanding the Hispanic paradox," Ethnicity \& Disease, vol. 11, no. 3, pp. 496$518,2001$.

[20] R. J. Shaw and K. E. Pickett, "The health benefits of hispanic communities for non-hispanic mothers and infants: another hispanic paradox," The American Journal of Public Health, vol. 103, no. 6, pp. 1052-1057, 2013.

[21] L. N. Rubalcava, G. M. Teruel, D. Thomas, and N. Goldman, "The healthy migrant effect: new finding form the Mexican family life survey," American Journal of Public Health, vol. 98, no. 1, pp. 78-84, 2008.

[22] A. Palloni and E. Arias, "Paradox lost: explaining the Hispanic adult mortality advantage," Demography, vol. 41, no. 3, pp. 385$415,2004$.
[23] S. H. Ullmann, N. Goldman, and D. S. Massey, "Healthier before they migrate, less healthy when they return? The health of returned migrants in Mexico," Social Science and Medicine, vol. 73, no. 3, pp. 421-428, 2011.

[24] D. S. Massey and R. Zenteno, "A validation of the ethnosurvey: the case of Mexico-U.S. migration," International Migration Review, vol. 34, no. 3, pp. 766-793, 2000.

[25] Mexican Migration Project (MMP), "Study Design," http://mmp.opr.princeton.edu/research/studydesign-en.aspx.

[26] L. L. Wu, "Event history models for life course analysis," in Handbook of the Life Course, J. Mortimer and M. Shanahan, Eds., pp. 477-502, Plenum Press, New York, NY, USA, 2003.

[27] G. H. Elder Jr., "The life course as developmental theory," Child Development, vol. 69, no. 1, pp. 1-12, 1998.

[28] G. H. Elder, M. K. Johnson, and R. Crosnoe, "The emergence and development of life course theory," in Handbook of the Life Course, J. Mortimer and M. Shanahan, Eds., pp. 3-19, Plenum, New York, NY, USA, 2003.

[29] D. R. Cox, "Regression models and life tables (with discussion)," Journal of the Royal Statistical Society, Series B, vol. 34, no. 2, pp. 187-220, 1972.

[30] M. Cleves, W. Gould, R. G. Gutierrez, and Y. V. Marchenko, An Introduction to Survival Analysis Using Stata, Stata Press, College Station, Tex, USA, 3rd edition, 2008.

[31] S. Guendelman, P. Buekens, B. Blondel, M. Kaminski, F. C. Notzon, and G. Masuy-Stroobant, "Birth outcomes of immigrant women in the United States, France, and Belgium," Maternal and Child Health Journal, vol. 3, no. 4, pp. 177-187, 1999.

[32] F. Riosmena, R. Wong, and A. Palloni, "Migration selection, protection, and acculturation in health: a binational perspective on older adults," Demography, vol. 50, no. 3, pp. 1039-1064, 2013.

[33] S. P. Arévalo, K. L. Tucker, and L. M. Falcón, "Life events trajectories, allostatic load, and the moderating role of age at arrival from Puerto Rico to the US mainland," Social Science \& Medicine, vol. 120, pp. 301-310, 2014.

[34] B. M. Wen, "Stress, adaptation, and disease allostasis and allostatic load," Annals of the New York Academy of Sciences, vol. 840, no. 1, pp. 33-44, 1998.

[35] G. Engström, F. A. Khan, E. Zia et al., "Marital dissolution is followed by an increased incidence of stroke," Cerebrovascular Diseases, vol. 18, no. 4, pp. 318-324, 2004.

[36] G. Engström, B. Hedblad, M. Rosvall, L. Janzon, and F. Lindgärde, "Occupation, marital status, and low-grade inflammation: mutual confounding or independent cardiovascular risk factors?" Arteriosclerosis, Thrombosis, and Vascular Biology, vol. 26, no. 3, pp. 643-648, 2006.

[37] K. S. Kendler, L. M. Karkowski, and C. A. Prescott, "Causal relationship between stressful life events and the onset of major depression," American Journal of Psychiatry, vol. 156, no. 6, pp. 837-841, 1999.

[38] A.-J. Pyykkönen, K. Räikkönen, T. Tuomi, J. G. Eriksson, L. Groop, and B. Isomaa, "Stressful life events and the metabolic syndrome: the prevalence, prediction and prevention of diabetes (PPP)-botnia study," Diabetes Care, vol. 33, no. 2, pp. 378384, 2010.

[39] K. Räikköonen, K. A. Matthews, and L. H. Kuller, "Depressive symptoms and stressful life events predict metabolic syndrome among middle-aged women: a comparison of World Health Organization, Adult Treatment Panel III, and International Diabetes Foundation definitions," Diabetes Care, vol. 30, no. 4, pp. 872-877, 2007. 
[40] J. P. Stimpson, F. A. Wilson, and K. Eschbach, "Trends in health care spending for immigrants in the United States," Health Affairs, vol. 29, no. 3, pp. 544-550, 2010.

[41] S. P. Wallace, C. Mendez-Luck, and X. Castañeda, "Heading south: why Mexican immigrants in California seek health services in Mexico," Medical Care, vol. 47, no. 6, pp. 662-669, 2009. 

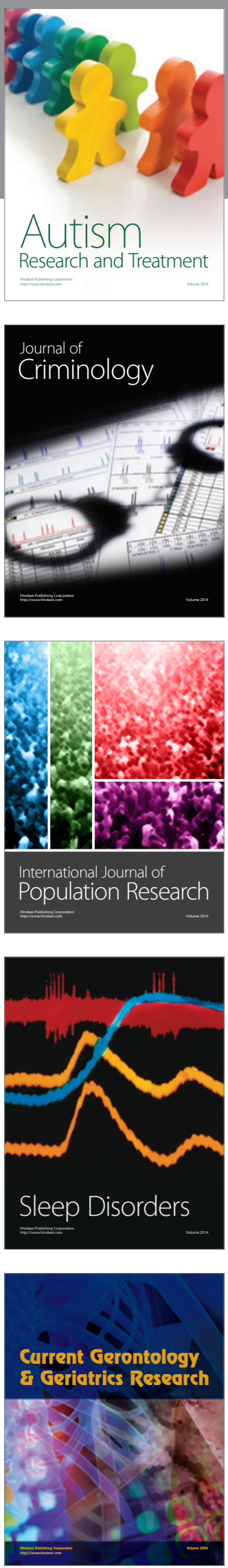
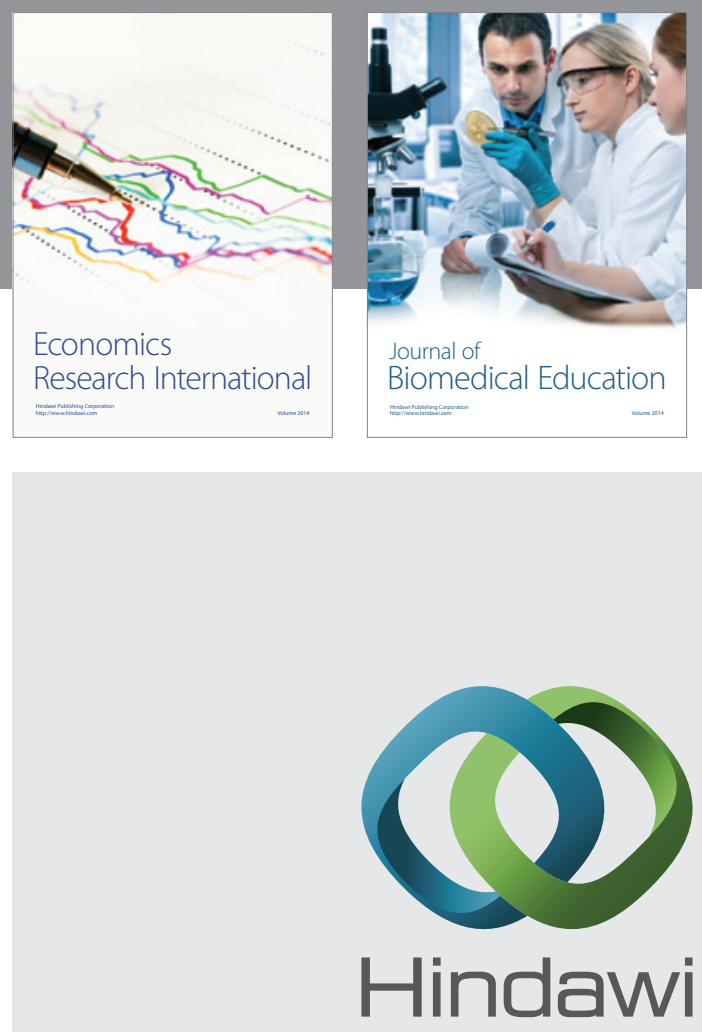

Submit your manuscripts at

http://www.hindawi.com
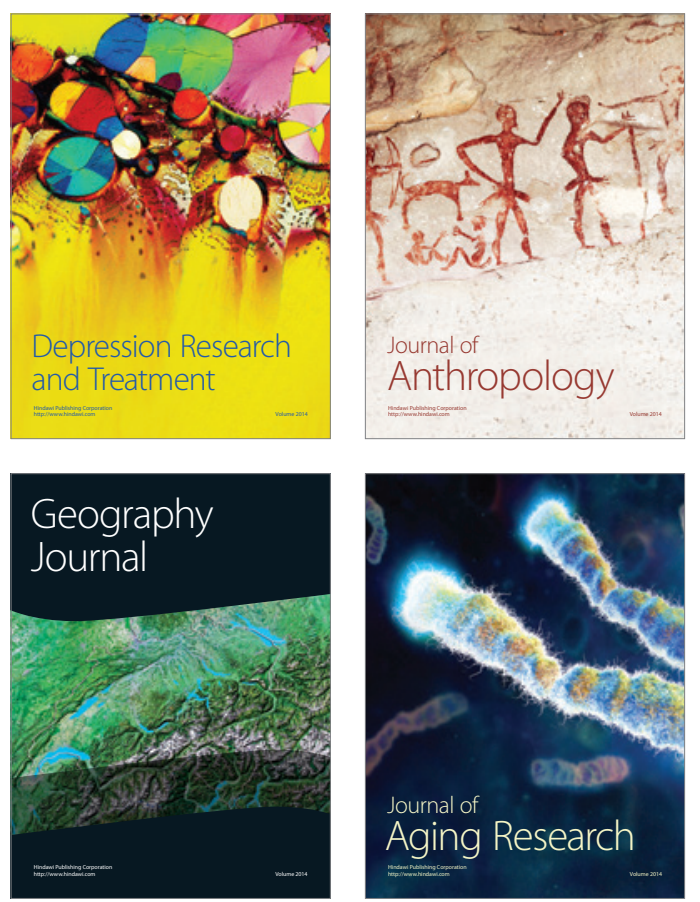
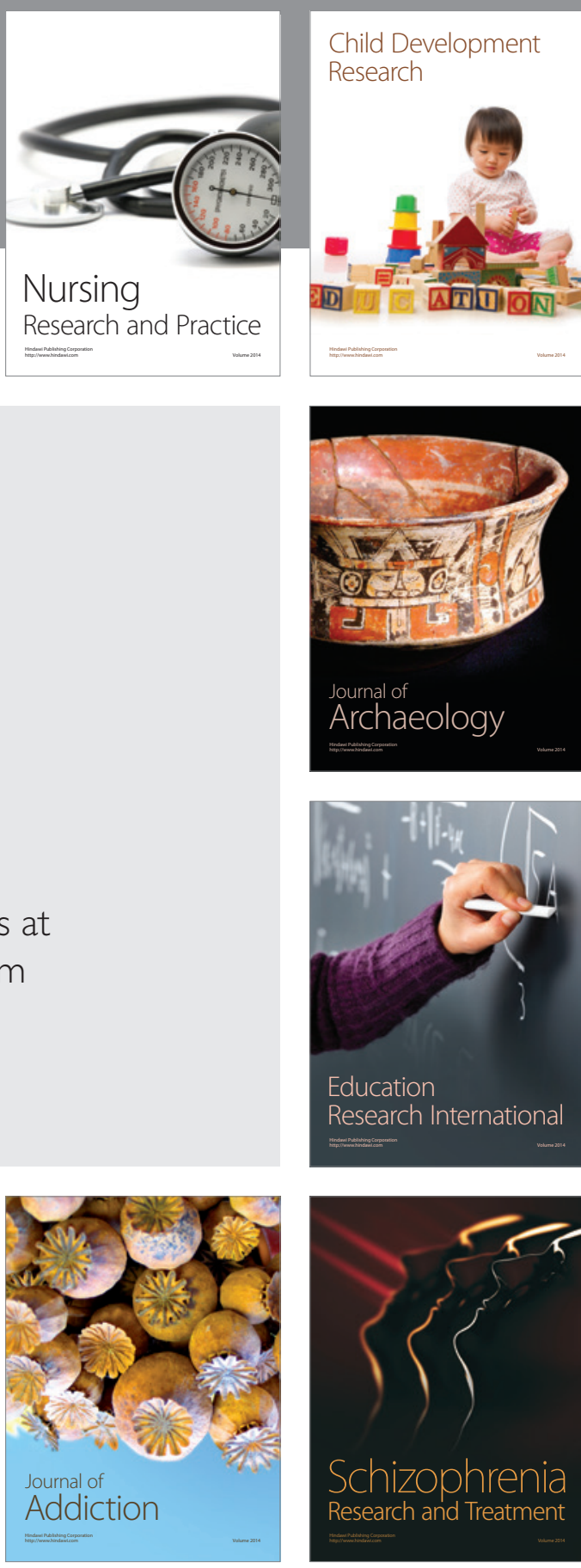

(D)
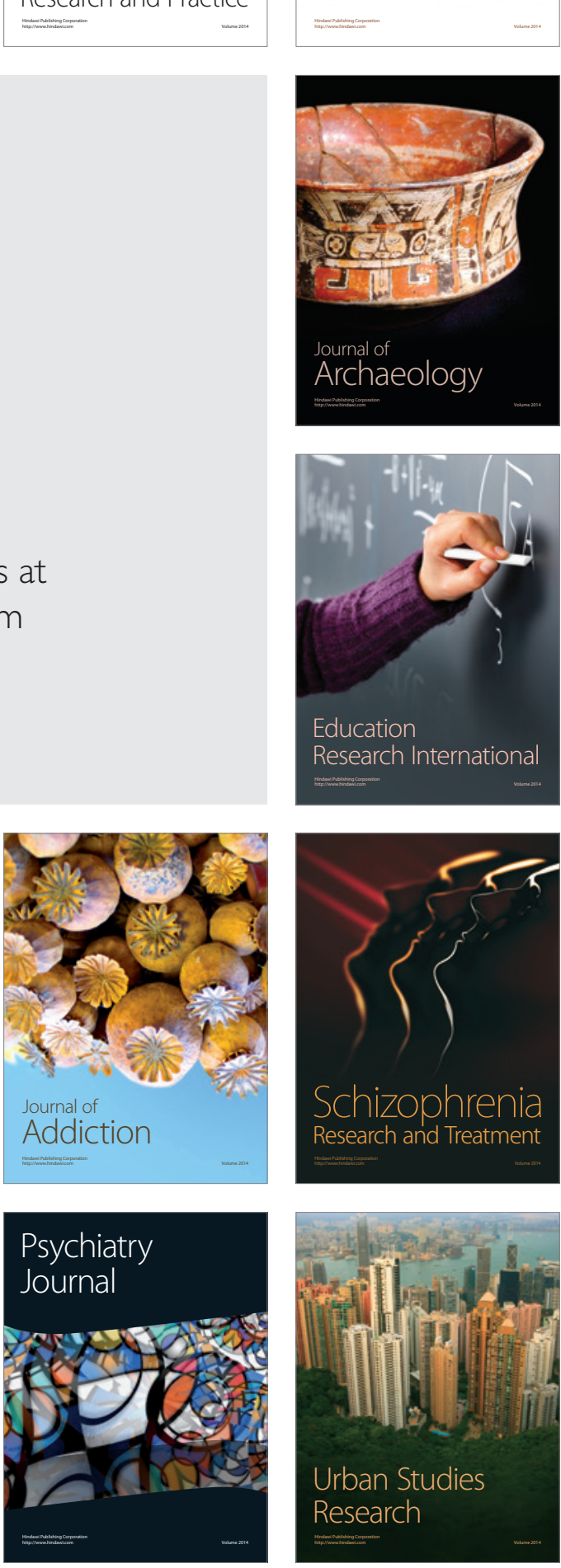